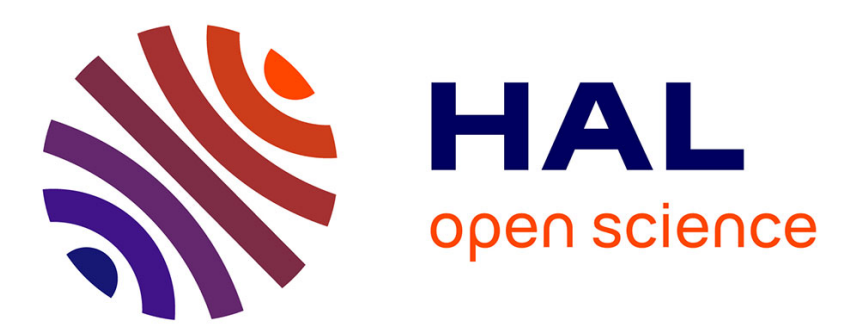

\title{
Male and female mound-building mice, Mus spicilegus, discriminate dietary and individual odours of conspecifics
}

\author{
Diane Colombelli-Négrel, Patrick Gouat
}

\section{- To cite this version:}

Diane Colombelli-Négrel, Patrick Gouat. Male and female mound-building mice, Mus spicilegus, discriminate dietary and individual odours of conspecifics. Animal Behaviour, 2006, 72 (3), pp.577583. hal-00269387

\section{HAL Id: hal-00269387 https://hal.science/hal-00269387}

Submitted on 3 Apr 2008

HAL is a multi-disciplinary open access archive for the deposit and dissemination of scientific research documents, whether they are published or not. The documents may come from teaching and research institutions in France or abroad, or from public or private research centers.
L'archive ouverte pluridisciplinaire HAL, est destinée au dépôt et à la diffusion de documents scientifiques de niveau recherche, publiés ou non, émanant des établissements d'enseignement et de recherche français ou étrangers, des laboratoires publics ou privés. 
1 Male and female mound-building mice, Mus spicilegus, discriminate dietary and individual

2 odours of conspecifics.

3

4 Diane COLOMBELLI-NEGREL \& Patrick GOUAT - Université Paris 13, LEEC - UMR

$5 \quad$ CNRS 7153, Villetaneuse, France

6

7 Running headline:

8 Colombelli-Négrel \& Gouat: Odour discrimination in mice

9

10

11

12

13 Corresponding author:

14 Patrick Gouat

15 Laboratoire Ethologie Expérimentale et Comparée

16 Université Paris 13, UMR CNRS 7153

1799 avenue Jean-Baptiste Clément

1893430 Villetaneuse France

19 Email: Patrick.Gouat@leec.univ-paris13.fr

20

21 Word count: 3727 
1 Abstract

2 Individual body odour is known to provide information to conspecifics about both the identity

3 and the biological state of the donor. It is not clear whether information related to

4 individuality and biological state is evaluated collectively or separately. To gain insight into

5 this subject, we examined the role of diet change for conspecific recognition of individual

6 chemical signatures in mound-building mice Mus spicilegus. The diet change consisted of the

7 addition of an aromatic concentrate to the drinking water. We used two different procedures

8 based on spontaneous responses of mice to the presentation of odorous stimuli: the

9 habituation-dishabituation procedure and the habituation-generalisation procedure. Mice of

10 both sexes were able to perceive the two types of information contained in the modified

11 chemical signature of the donor. Males and females were able to perceive the change of diet

12 and, despite this change of diet, mice were able to identify the chemical signature of a donor. 
1 Chemical communication is widespread in the animal world and constitutes, in rodents, a

2 prominent mode of communication. Olfaction represents the main sense by which rodents

3 recognize individuals and conspecifics, and acquire knowledge about their social environment

4 (Brown 1979). The study of individual recognition by chemical cues presents an interesting

5 problem at the evolutionary level. On the one hand, species specificity requires a high degree

6 of homogeneity from one individual to another. On the other hand, individual identification

7 requires that each individual has a chemical signature that differs from conspecifics (Halpin $8 \quad 1980)$

The individual chemical signature may be defined as the complete set of odorants produced by the body of a given individual that allows unambiguous identification. It has been shown that individual characteristics, conveyed by these odorous productions, allow the recognition of an individual (Gheusi et al. 1994; Johnston \& Jernigan 1994; Gheusi et al. 1997), at both cognitive and functional levels (Gosling 1990; Gosling \& McKay 1990; Randall 1991). This property of the individual chemical signature is predicted to be related to an individual's genomic structure. Many studies have suggested a link between the individual chemical signature and a precise section of the genome (see Brennan 2004 for review).

Odours are known to convey information about the state of an individual (e.g., reproductive state, age, diet). Several studies have shown the influence of diet on olfactory cues. In meadow voles, Microtus pennsylvanicus, for example, an increase in protein content of the diet increased the attractiveness of odorous marks (Ferkin et al. 1997). In rats, genetic

21 differences in the Major Histocompatibility Complex (MHC), bacterial flora, and diet 22 interacted to produce the individual chemical signature (Brown \& Schellinck 1992; Brown 1995). It was shown, moreover, that rats found it easier to discriminate between urinary odours of two MHC-congenic mice after mice consumed different diets (Brown et al. 1996). It was also easier for these rats to remember the differences between the urinary odours of 
1 genetically identical mice maintained under different diets than to remember the differences

2 between MHC-congenic mice sharing the same diet (Schellinck et al. 1997). In order to be

3 functional, however, the individual chemical signature depends on stability. Indeed, any

4 sudden change in this individual chemical signature could disturb the normal social

5 relationship of an established group (Halpin 1980). Consequently, one may ask whether

6 individuality is the result of information related to the biological state and the genetic identity

7 of the individual, and whether biological state and genetic identity are distinct. To gain insight

8 into this subject, we investigated whether a change of diet could disturb the recognition of the

9 individual chemical signature by a conspecific in mound-building mice, Mus spicilegus.

M. spicilegus, a mouse of eastern and central Europe (Sokolov et al. 1998), differs

11 dramatically from other species of mice. Monogamous (Patris \& Baudoin 1998; Patris \&

12 Baudoin 2000; Dobson \& Baudoin 2002; Patris et al. 2002, Gouat \& Féron 2005), this species

13 is characterized by building mounds during Autumn (Orsini et al. 1983; Garza et al. 1997)

14 where mice stay during the winter without reproduction. During this winter cloistering, mice

15 become familiar with each other, which is responsible for the inhibition of their reproduction

16 (Gouat et al. 2003a). In spring, individuals leave the mounds, and reproduction begins after

17 pairing with unfamiliar individuals (Gouat et al. 2003b). Given the major role played by individual recognition in M. spicilegus, this species seemed appropriate for the proposed study. Moreover, it has been shown that male M. spicilegus were able to discriminate between the olfactory signatures of two conspecific males (Gouat et al. 1998). In the present study, we used different habituation procedures to test if a change of diet can be detected by mice, and whether, in spite of this change of diet, mice are still able to recognize an individual chemical signature. Males and females were used as experimental animals, and donors were males. Because females are thought to play a prominent role in mate choice (Andersson 1994), we expected females to discriminate between individual signatures of males. 


\section{METHODS}

\section{Animals and breeding conditions}

We used mice derived from 80 wild animals caught in Hungary in 1999 (Gouat et al. 2003a), and reared in captivity for five generations. Thirty-two adult males and twenty-two adult females (both between 3 and 11 months old) were used. They originated from twenty different breeding pairs. Mice were kept under controlled laboratory conditions $\left(20^{\circ} \mathrm{C}, 14: 10\right.$ $\mathrm{h}$ light:dark cycle). During the dark phase, the room was lit by a dimmed red-light (two neon tubes, $35 \mathrm{~W}$ ) allowing observation. Mice were housed in standard polycarbonate cages $(26 \times 14 \times 16 \mathrm{~cm})$ with sawdust (Special Diet Services, Witham, Essex, GB). Cotton wool was provided for nesting material. Food (type M20, Special Diet Services, Witham, Essex, GB) and water were supplied ad libitum.

Animals were weaned at 28 days of age, and, one week later, they were placed in same-sex sibling groups. At this time, when an animal was left alone (only one male or one female inside a litter), it was placed with another sibling group of the same age and sex. One week before the experiment, we took experimental individuals from these sibling groups and placed them in same-sex pairs in new clean cages. Animals were identified by hair clipping. Odour donors and subjects were different animals.

\section{Samples}

We used soiled sawdust, referred to as sawdust sample, (with urine and droppings from donor mice), which has been shown to convey chemical signatures (Gouat et al. 1998; 
1 Maslak \& Gouat 2002). Consequently, donors were isolated one week before the experiment.

2 Only adult males were used as donors because isolation may have modified the reproductive

3 state of females (Féron \& Gheusi 2003). The diet change involved the addition of an aromatic

4 concentrate to the drinking water. Antésite (Antésite S.A., Voiron, France) is an aromatic

5 concentrate that can be used in human drink water. Liquorice is an essential ingredient that

6 can come with several aromas. We chose anise aroma because it was well tolerated by mice

7 (Tourrain \& Gouat, unpublished data), and contains neither alcohol nor sugar. Therefore, the

8 diet was not modified by caloric intake, which could have an influence on the attractiveness

9 of odorous marks (Ferkin et al. 1997). The basic amount used (1.33g/l) corresponded to the concentration recommended by the manufacturer. We will refer, thereafter, to these two diets

11 as Water diet and Anise diet.

Sawdust samples were collected during a two week period. First, animals were placed in a clean cage with clean sawdust and received the usual Water diet. After three days the soiled sawdust was collected in a freezer bag, closed hermetically and placed at $-10^{\circ} \mathrm{C}$ until required. Afterwards, animals were placed in a new cage with clean sawdust and received the Anise diet. After three days, sawdust samples were collected again, in the same way. As a consequence, Water samples were frozen for a longer period of time (i.e., three days) than the Anise samples. In order to avoid possible bias due to this difference in freezing time, we carried out a third series of sawdust sampling. This time, animals were placed again in the same cage with clean sawdust and received the Water diet. In order to eliminate Anise

21 residues which could persist just after this change of diet, the sawdust, as well as the cages, 22 were again changed the following day. Three days later, sawdust samples were collected again in the same way. For each experiment, the two Water samples were used alternatively.

24 No effect of the freezing time was detected, so the data from the two types of Water diet 25 sawdust samples were pooled. 
Procedures

3

The procedures used in the present study were based on spontaneous responses of mice to the presentation of odorous stimuli. Under these circumstances, animals only respond to stimuli that have importance for them. These procedures are recognized to be ecologically and functionally valid (Schellinck \& Brown 1994; Schellinck et al. 1995). The additional interest of these procedures comes from the simplicity of their design. These procedures have already been used with success in wild animals (Vaché et al. 2001), including M. spicilegus (Gouat et al. 1998; Heth et al. 2001; Heth et al. 2003).

To determine whether mice respond to the change of diet as reflected by the donor's odorous productions, we used a habituation-dishabituation procedure (Halpin 1980, Johnston et al. 1993). Subjects were presented with sawdust soiled by a donor on the Water diet for three successive trials (habituation phase). We always used Water diet during the habituation phase because this stimulus was less novel for the subject as they had not been exposed previously to the odour of Anise. On the fourth trial (dishabituation phase), we presented sawdust soiled by the same donor but on the Anise diet. Two types of results may be expected.

On the one hand, the investigation time of the soiled sawdust could increase significantly between the third and the forth trials and we could conclude that mice perceived the change of diet. In order to test if mice were able to recognize the chemical signature of a donor in spite of a change of diet we used a habituation-generalisation procedure (Todrank et al. 1998) with two donors and a change of diet. During the habituation phase, subjects were presented with sawdust soiled by a donor on the Water diet. On the fourth trial, we presented simultaneously sawdust soiled by the habituation donor and sawdust soiled by an unknown 
1 donor, both on the Anise diet. If subjects spent more time investigating the sawdust soiled by

2 the second donor, we could conclude that subjects considered that odours of the new donor on

3 the Anise diet differed more from the habituation stimulus than odours of the habituation

4 donor on the Anise diet. This result would suggest that mice were able to recognize the

5 individual chemical signature in spite of the change of diet.

On the other hand, the investigation time could not increase significantly with the change of diet. When a habituation-dishabituation procedure is used, a null result is difficult to interpret. It is difficult to establish the difference between an absence of response due to a lack of interest and an absence of response due to inability to discriminate. A systematic lack of response to the stimuli could not be considered as an absence of detection (Schellinck \& Brown 1994), but may reveal that the subject does not respond to the stimuli in this context (Todrank \& Heth 2003). In order to distinguish between these interpretations, we used a different type of habituation-dishabituation procedure. During the habituation phase, subjects were presented with sawdust soiled by a donor on the Water diet. On the fourth trial, we presented simultaneously two dishes of sawdust soiled by the habituation donor, one on the Water diet and the other on the Anise diet. It is thought that this two-stimulus testing paradigm should be easier than a single stimulus trial: the subject can compare the two stimuli directly rather than compare the novel stimulus to the memory of the habituation stimulus (Johnson \& Peng 2000). If subjects spent significantly more time investigating the Anise diet stimulus than the Water diet stimulus, we could conclude that they perceived the change of 21 diet.

The procedure was the same for both males and females. However, discriminative responses of $M$. spicilegus females had never been studied in this paradigm. Therefore, we

24 first tested whether females respond to a change of donor on the Water diet using a 
1 habituation-dishabituation procedure. All females were in anoestrus during the experiments as

2 shown by their closed vagina (Féron \& Gheusi 2003).

3

4

5

6

7

\section{Experimental conditions}

Discrimination tests were carried out during the beginning of the dark phase (first five hours). Ten minutes before the test, we took and defrosted only the necessary quantity of soiled sawdust. Samples were kept for only two weeks after collection.

Experiments were performed in the home cage of the experimental mouse to avoid possible bias due to the stress of a transfer to a new environment (Burman \& Mendl 2002).

Subjects were housed in pairs, and the non-tested individual was taken out of the cage ten minutes before the test and placed in a clean cage without sawdust. At the end of the test, the mouse was returned to the cage and was only tested the following day. Animals were tested in the same way but they were not tested with the same donors nor with donors of similar origins. Donors were assigned to an experimental mouse at random following the rule that the animals were unfamiliar and from different origins. In a given experiment each combination of the origins of a subject and donors was only used once.

Two plastic dishes (3.5 cm diameter), fixed to a support (figure 1), so that mice could not displace or overturn them, were placed in the cage of an experimental mouse opposite the nest (Maslak \& Gouat 2002). Two dishes containing sawdust soiled or not, were always presented whatever the procedure. When only one odour stimulus was presented, the second dish contained clean sawdust. Clean sawdust checked the validity of the stimulus presented (first trial) and showed that an increase in investigation time observed in the fourth trial was for the soiled sawdust only. A trial lasted 5 minutes and started when the animal left its nest 
1 and moved towards the support. The time spent investigating the sawdust by the experimental

2 mouse was measured during each trial with a stop-watch. Experiments were also monitored

3 by a video camera. Investigation was defined to occur when the nose of the animal was $1 \mathrm{~cm}$

4 or less above the dish, or when the animal was scratching in the dish.

\section{Ethical note}

Donors were isolated for a three-week period (one week before collection of samples, and two weeks during samples collection). To bring adult mice back to their sibling groups after three weeks of isolation may have caused a high level of aggression. To avoid this, donors were sacrificed by asphyxiation in a high concentration of carbon dioxide at the end of the collecting period. The samples were kept during two weeks in the freezer, and we collected enough soiled saw-dust to be used in different experiments. As a result, only 11 males were used as donors in the five different experiments. The number of combinations of the origins of donors and subjects was sufficient to avoid pseudo-replication problems.

All the experimental procedures were approved by the Ile-de-France Regional Ethics Committee in Animal Experiment number 3 (approval: p3/2004/005).

\section{Data analysis}

Because of the small number of animals in each group $(\mathrm{N} \leq 15)$, we used nonparametric statistics and exact procedures (Mundry \& Fischer 1998). Tests were performed on StatXact (Cytel Software Corporation, Cambridge, MA, USA). Two different types of comparisons were made according to the question. Paired comparisons were carried 
1 out using a permutation test. Permutation tests give the exact probability of occurrence of

2 such or more extreme distributions than the observed distribution.

In order to check the occurrence of a habituation process, we compared investigation

4 time for soiled sawdust between the first and the third trial. For a habituation-dishabituation

5 procedure (experiments 1, 3 and 4), we compared the duration of investigation of soiled sawdust between the third and the fourth trial to determine the effect of change (donor change or diet change). The duration of investigation on the third trial was used twice. To prevent a type I error we used the sequentially rejective Bonferroni procedure (Holm 1979), and the

9 threshold of significance was lowered to $\alpha=0.025$ for two comparisons. In experiments 2 and 5 , the second comparison tested the difference of duration of investigation between the two soiled sawdust presented on the fourth trial. Before these two paired comparisons, a Friedman analysis of variance (exact procedure) was carried out on the complete set of investigation 13 times used.

\section{RESULTS}

Males

Experiment 1: same donor on two different diets

Twelve subjects were tested (five different origins) with the odours of six donors (six different origins).

The investigation time across the three trials (Fig. 2) was significantly different $\left(\chi_{\mathrm{r}}^{2}=\right.$

$2412.17 ; p=0.002$ ). Investigation time for soiled sawdust decreased significantly between the

25 first and the third trial of the habituation phase $(p=0.004)$. Experimental animals 
1 significantly increased their investigation time for soiled sawdust during the fourth trial $(\mathrm{p}=$

$20.013)$

3

$4 \quad$ Experiment 2: two diets and two donors

A habituation-generalisation procedure with two donors and a change of diet was

used. During the habituation procedure, subjects were presented with sawdust soiled by a donor on the Water diet. On the fourth trial, we presented simultaneously sawdust soiled by the habituation donor and sawdust soiled by an unknown donor, both on the Anise diet. Nine males were tested (four different origins) with the odours of five donors (five different

11 origins).

The investigation time across the three trials (Fig. 3) was significantly different $\left(\chi \mathrm{r}^{2}=\right.$ 16.73; $\mathrm{p}<0.001)$. A habituation process occurred between the first and the third trial $(\mathrm{p}=$ 0.020). During the fourth trial, M. spicilegus males spent more time investigating the sawdust soiled by the unknown donor than the sawdust soiled by the habituation donor, despite the 16 change of diet $(\mathrm{p}=0.004)$.

Females

Experiment 3: change of donors

Seven females were tested (six different origins) with the odours of six donor males (six different origins).

The investigation time across the three trials (Fig. 4) was significantly different $\left(\chi_{\mathrm{r}}^{2}=\right.$ $2510.29 ; \mathrm{p}=0.004)$. The decrease in investigation time for soiled sawdust between the first and 
1 the third trial showed that M. spicilegus females habituated to the odour of the first donor on

2 the Water diet $(p=0.016)$. During the fourth trial, females increased their investigation time

3 for sawdust soiled by the second donor $(p=0.031)$

4

$5 \quad$ Experiment 4: same donor on two different diets

6

The odours of five donors (five different origins) were used to test eight females (four different origins).

The investigation time across the three trials (Fig. 5) was significantly different $\left(\chi_{\mathrm{r}}^{2}=\right.$ $9.75 ; \mathrm{p}=0.005)$. A habituation process occurred between the first and the third trial $(\mathrm{p}=$ $0.023)$ but no increase was detected in the fourth trial $(p=0.305)$. In fact, investigation time decreased in five out of the eight tested females (four different origins).

\section{Experiment 5 : change of diet}

According to the result of experiment 4 , a modified habituation-dishabituation procedure was carried out. During the habituation procedure, we presented sawdust soiled by a donor on the Water diet. In the fourth trial, we presented simultaneously two dishes of sawdust soiled by the habituation donor, one on the Water diet and the other on the Anise diet. Seven females (six different origins) were tested with the odours of five donors (five different origins).

The investigation time across the three trials (Fig. 6) was significantly different $\left(\chi_{\mathrm{r}}^{2}=\right.$ 14.91; $\mathrm{p}<0.001)$. M. spicilegus females habituated to the odour of the first donor on the Water diet, as was shown by the decrease in investigation time of soiled sawdust between the 
1 first and the third trial $(p=0.016)$. In the fourth trial, females spent more time investigating

2 the sawdust soiled by the donor on the Anise diet than on the Water diet $(p=0.047)$.

3

\section{DISCUSSION}

The change of diet used in these experiments was clearly perceived by males as shown in experiment 1 . The results of experiment 2 suggested that, despite the change of diet, males perceived the change of donor during the generalisation phase.

The results of experiment 3 showed that females reacted to the change of donor on the Water diet and consequently were able to discriminate between the olfactory signatures of two donor males. Females responded similarly to males in previous tests (Gouat et al. 1998).

Nevertheless, responses of females to a change of diet of the donor (experiment 4) differed from the responses of males confronted with a similar change (experiment 1). In fact, females did not respond to the change of diet of the donor, and investigation time of the soiled sawdust even tended to decrease. Although this decrease between investigation time of the soiled sawdust between trials three and four was far from significant, this result was similar to that observed when the habituation phase included four trials or more (Gouat et al. 1998, Maslak \& Gouat 2003). Females behaved as though the chemical signature of the donor was not altered by the change of diet. A problem with the samples of soiled sawdust can be excluded, because the same sawdust samples were successfully used in other experiments with both male (experiments 1 and 2) and female subjects (experiment 5). In experiment 5 , nevertheless, females were able to discriminate between the two types of diet when the two stimuli were presented in the same trial. These results suggested that during experiment 4 , the two types of information were perceived by the females, but that females simply did not respond to the changes presented, an inherent problem with experimental tests that depend on 
1 spontaneous responses. These difficulties are overcome, however, through examining the two

2 sets of results together; in this case it becomes clear that - despite this change of diet - both

3 males and females were able to identify the chemical signature of the habituation donor.

Our data revealed that mound-building mice were able to react, in a relatively

5 independent way, to the state and trait information simultaneously evident in conspecific

6 odours. The fact that mice were able to perceive this information in parallel provides

7 important insights into the multiple functions played by individual odours. Variations of

8 hormonal level, diet, and bacterial flora have all been shown to affect individual odours

9 (Brown 1987). It has also been shown in multiple rodent species that close genetic relatedness

10 (i.e., genetic similarity) between individuals is associated with closer perceptual similarity in

11 their odours ("odour-gene covariance") but that each individual odour is as unique as the

12 individual genotype (Todrank \& Heth 2003). Every odorant directly linked with a part of the

13 genome, especially those with a high level of polymorphism, may contribute to the production

14 of chemical signature (Brennan 2004). Our results, in conjunction with those of previous

15 studies (reviewed in Todrank \& Heth 2003), suggest that individual odours are perceived as

16 composites that provide multiple types of information simultaneously. Future

17 neurophysiological studies will be necessary to determine how the brain processes and sorts

18 the various types of information available in individual odours.

\section{ACKNOWLEDGEMENTS}

21 Nicolas Busquet provided helpful comments on the manuscript. We thank Lavinia Bruneau 22 and Sonia Kleindorfer for the revision of the English, and Simone Demouron for her help in caring for animals. Jo Todrank provided invaluable comments on the revised version of the manuscript. 


\section{REFERENCES}

2 Andersson, M. B. 1994. Sexual selection. Princeton: Princeton University Press.

3 Brennan, P. A. 2004. The nose knows who's who: chemosensory individuality and mate

4 recognition in mice. Hormones and Behavior, 46, 231-240.

5 Brown, R. E. 1979. Mammalian social odors: a critical review. Advances in the study of

6 behavior, 10, 103-162

7 Brown, R. E. 1987. Individual odors of rats are discriminable independently of changes in gonadal hormone levels. Physiology and Behavior, 43, 359-363.

Brown, R. E. 1995. What is the role of the immune system in determining individually distinct body odours? International Journal of Immunopharmacology, 17, 655-661.

Brown, R. L. \& Schellinck, H. M. 1992. Interactions among the MHC, diet and bacteria in the production of social odors in rodents. In: Chemical signals in Vertebrates VI (Ed. by Müller-Schwarze, D.), pp. 175-181. New York: Plenum Press.

Brown, R. E., Schellinck, H. M. \& West, M. 1996. The influence of dietary and genetic cues on the ability of rats to discriminate between the urinary odors of MHC-congenic mice. Physiology and Behavior, 60, 365-372.

Burman, O. H. P. \& Mendl, M. 2002. Recognition of conspecific odors by laboratory rats (Rattus norvegicus) does not show context specificity. Journal of Comparative Psychology, 116, 247-252.

Dobson, F. S. \& Baudoin, C. 2002. Experimental tests of spatial association and kinship in

21 monogamous mice (Mus spicilegus) and polygynous mice (Mus musculus domesticus).

22 Canadian Journal of Zoology, 80, 980-986.

Ferkin, M. H., Sorokin, E. S., Johnston, R. E. \& Lee, C. J. 1997. Attractiveness of scents varies with protein content of the diet in meadow voles. Animal Behaviour, 53, 133-141. 
1 Féron, C. \& Gheusi, G. 2003. Social regulation of reproduction in the female mound-builder

2 mouse (Mus spicilegus). Physiology and Behavior, 78, 717-722.

3 Garza, J. C., Dallas, J., Duryadi, D., Gerasimov, S., Croset, H. \& Boursot, P. 1997. Social

$4 \quad$ structure of the mound-building mouse Mus spicilegus revealed by genetic analysis with

5 microsatellites. Molecular Ecology, 6, 1009-1017.

6 Gheusi, G., Bluthé, R.-M., Goodall, G. \& Dantzer, R. 1994. Social and individual

7 recognition in rodents: methodological aspects and neurobiological bases. Behavioural

$8 \quad$ Processes, 33, 59-88.

9 Gheusi, G., Goodall, G. \& Dantzer, R. 1997. Individually distinctive odours represent individual conspecifics in rats. Animal Behaviour, 53, 935-944.

11 Gosling, L. M. 1990. Scent marking by resource holders: alternative mechanisms for 12 advertising the costs of competition. In: In: Chemical signals in Vertebrates (Ed. by Macdonald, D. W., Natynczuk, S. \& Müller-Schwarze, D.), pp. 315-328. Oxford: Oxford 14 University Press.

Gosling, L. M. \& McKay, H. V. 1990. Competitor assessment by scent matching: an experimental test. Behavioral Ecology and Sociobiology, 26, 415-420.

17 Gouat, P. \& Féron, C. 2005. Deficit in reproduction in polygynously mated females of the monogamous mound-building mouse Mus spicilegus. Reproduction, Fertility and Development, $\mathbf{1 7}$, in press.

Gouat, P., Patris, B. \& Lalande, C. 1998. Conspecific and heterospecific behavioural

21 discrimination of individual odours by mound-building mice. Comptes Rendus de l'Académie des Sciences Paris, Sciences de la vie, 321, 571-575.

23 Gouat, P., Féron, C. \& Demouron, S. 2003a. Seasonal reproduction and delayed sexual 24 maturity in mound-building mice Mus spicilegus. Reproduction, Fertility and Development, 15, 187-195. 
1 Gouat, P., Katona, K. \& Poteaux, C. 2003b. Is the socio-spatial distribution of mound-

2 building mice, Mus spicilegus, compatible with a monogamous mating system? Mammalia,

$3 \quad 67,15-24$

4 Halpin, Z. T. 1980. Individual odors and individual recognition: review and commentary.

5 Biology of Behaviour, 5, 233-248.

6 Heth, G., Todrank, J., Busquet, N. \& Baudoin, C. 2001. Odour-genes covariance and

7 differential investigation of individual odours in the Mus species complex. Biological Journal

8 of the Linnean Society, 73, 213-220.

9 Heth, G., Todrank, J., Busquet, N. \& Baudoin, C. 2003. Genetic relatedness assessment through individual odour similarities in mice. Biological Journal of the Linnean Society, 78,

$11595-603$.

12 Holm, S. 1979. A simple sequentially rejective multiple test procedure. Scandinavian Journal of Statistics, 6, 65-70.

Johnston, R. E. \& Jernigan, P. 1994. Golden hamsters recognize individuals, not just individual scents. Animal Behaviour, 48, 129-136.

Johnston, R. E. \& Peng, M. 2000. The vomeronasal organ is involved in discrimination of

17 individual odors by males but not by females in golden hamsters. Physiology and Behavior, 70, 537-549.

Johnston, R. E., Derzie, A., Chiang, G., Jernigan, P. \& Lee, H.-C. 1993. Individual scent signatures in golden hamsters: evidence for specialization of function. Animal Behaviour, 45,

21 1061-1070.

22 Maslak, S. \& Gouat, P. 2002. Short-term contact elicits heterospecific behavioral 23 discrimination of individual odors in mound-building mice Mus spicilegus. Journal of 24 Comparative Psychology, 116, 357-362. 
1 Mundry, R. \& Fischer, J. 1998. Use of statistical programs for nonparametric tests of small

2 samples often leads to incorrect P values: examples from Animal Behaviour. Animal

3 Behaviour, 56, 256-259

4 Orsini, P., Bonhomme, F., Britton-Davidian, J., Croset, H., Gerasimov, S. \& Thaler, L.

5 1983. Le complexe d'epèces du genre Mus en Europe Centrale et Orientale. II. Critères

6 d'identification, répartition et caractéristiques écologiques. Z. Säugetierkunde, 48, 86-95.

7 Patris, B. \& Baudoin, C. 1998. Female sexual preferences differ in Mus spicilegus and Mus musculus domesticus: the role of familiarization and sexual experience. Animal Behaviour, 56, $1465-1470$.

Patris, B. \& Baudoin, C. 2000. A comparative study of patrental care between two rodent

11 species: impliations for the mating system of the mound-building mouse Mus spicilegus.

Behavioural Processes, 51, 35-43.

13 Patris, B., Gouat, P., Jacquot, C., Christophe, N. \& Baudoin, C. 2002. Agonistic and 14 sociable behaviors in the mound-building mice, Mus spicilegus: a comparative study with Mus musculus domesticus. Aggressive Behavior, 28, 75-84.

Randall, J. A. 1991. Sandbathing to establish familiarity in the Merriam's kangaroo rat, Dipodomys merriami. Animal Behaviour, 41, 267-275.

Schellinck, H. M. \& Brown, R. E. 1994. Methodological questions in the study of the rat's ability to discriminate between the odours of individual conspecifics. Advances in the Biosciences, 93, 427-436.

21 Schellinck, H. M., Rooney, E. \& Brown, R. E. 1995. Odors of individuality of germfree 22 mice are not discriminated by rats in a habituation-dishabituation procedure. Physiology and Behavior, 57, 1005-1008. 
1 Schellinck, H. M., Slotnick, B. M. \& Brown, R. E. 1997. Odors of individuality originating

2 from the major histocompatibility complex are masked by diet cues in the urine of rats.

3 Animal Learning \& Behavior, 25, 193-199.

4 Sokolov, V. E., Kotenkova, E. V. \& Michailenko, A. G. 1998. Mus spicilegus. Mammalian

5 Species, 592, 1-6.

6 Todrank, J., Heth, G. \& Johnston, R. E. 1998. Kin recognition in golden hamsters:

7 evidence for kinship odours. Animal Behaviour, 55, 377-386.

8 Todrank, J. \& Heth, G. 2003. Odor-gene covariance and genetic relatedness assessments:

9 Rethinking odor-based "recognition" mechanisms in rodents. In: Advances in the Study of

10 Behavior, pp. 77-130. London: Academic Press.

11 Vaché, M., Ferron, J. \& Gouat, P. 2001. The ability of red squirrels (Tamiasciurus

12 hudsonicus) to discriminate conspecific olfactory signatures. Canadian Journal of Zoology,

13 79, 1296-1300. 
1 Figure 1. The testing device with a mouse investigating the dish on the right side.

2

3 Figure 2. Time spent by male mound-building mice $(\mathrm{N}=12)$ investigating the sawdust during

4 a habituation-dishabituation procedure with one donor and a change of diet.

5 Legend: clean sawdust (white bars), sawdust soiled by a donor male under Water diet (black

6 bars); sawdust soiled by the same donor male under Anise diet (hatched bars).

7

8 Figure 3 . Time spent by male mound-building mice $(\mathrm{N}=9)$ investigating the sawdust during a

9 habituation-generalization procedure with two donors and a change of diet.

Legend: clean sawdust (white bars), sawdust soiled by male donor A under Water diet (black

11 bars); sawdust soiled by male donor A under Anise diet (hatched bars); sawdust soiled by male donor B under Anise diet (horizontally hatched bars).

Figure 4. Time spent by female mound-building mice $(\mathrm{N}=7)$ investigating the sawdust during a habituation-dishabituation procedure with two donors under Water diet. Legend: clean sawdust (white bars), sawdust soiled by male donor A (black bars); sawdust soiled by male donor B (hatched bars).

Figure 5. Time spent by female mound-building mice $(\mathrm{N}=8)$ investigating the sawdust during a habituation-dishabituation procedure with one donor and a change of diet. Legend: clean sawdust (white bars), sawdust soiled by a donor male under Water diet (black bars); sawdust soiled by the same donor male under Anise diet (hatched bars).

24 Figure 6. Time spent by female mound-building mice $(\mathrm{N}=9)$ investigating the sawdust during a habituation-dishabituation procedure with one donor and two diets. 
1 Legend: clean sawdust (white bars), sawdust soiled by male donor A under Water diet (black

2 bars); sawdust soiled by male donor A under Anise diet (hatched bars) 
1
2
3
4
5
6

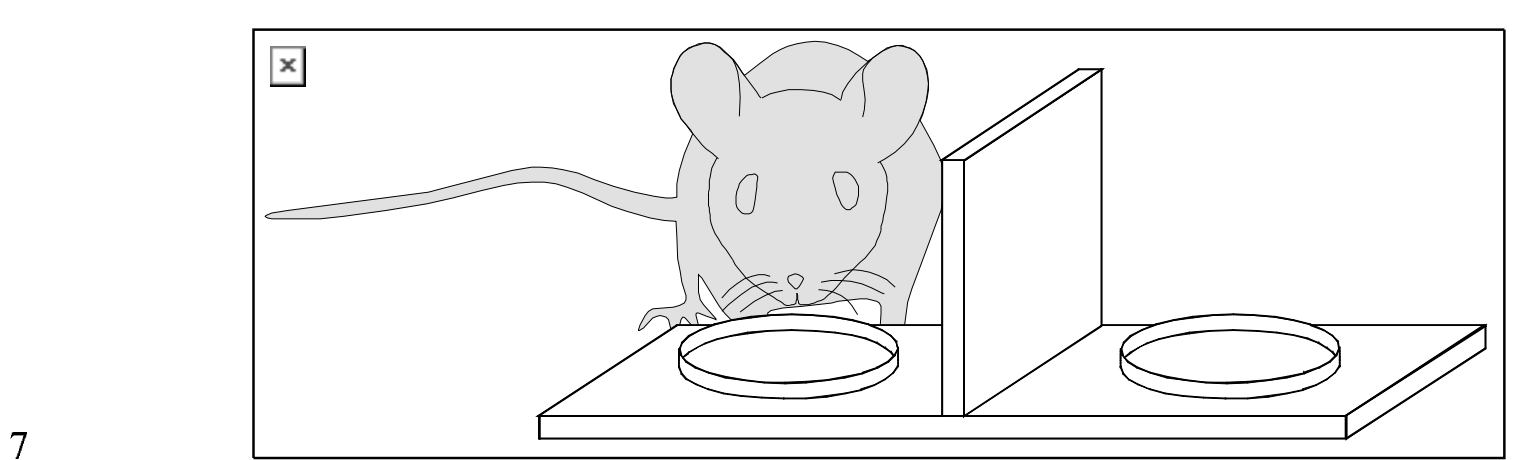

8

Fig. 1 
1

2

3

4

5

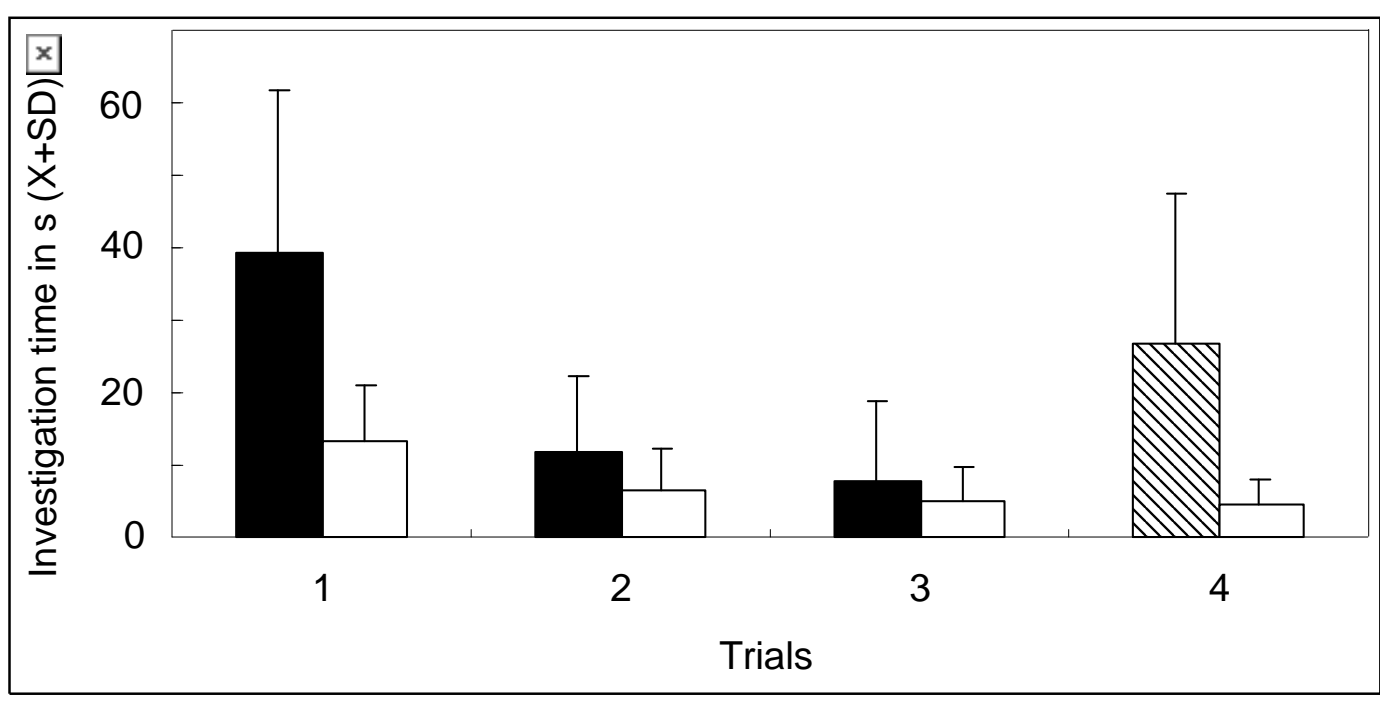

7

Fig. 2 
1
2
3
4

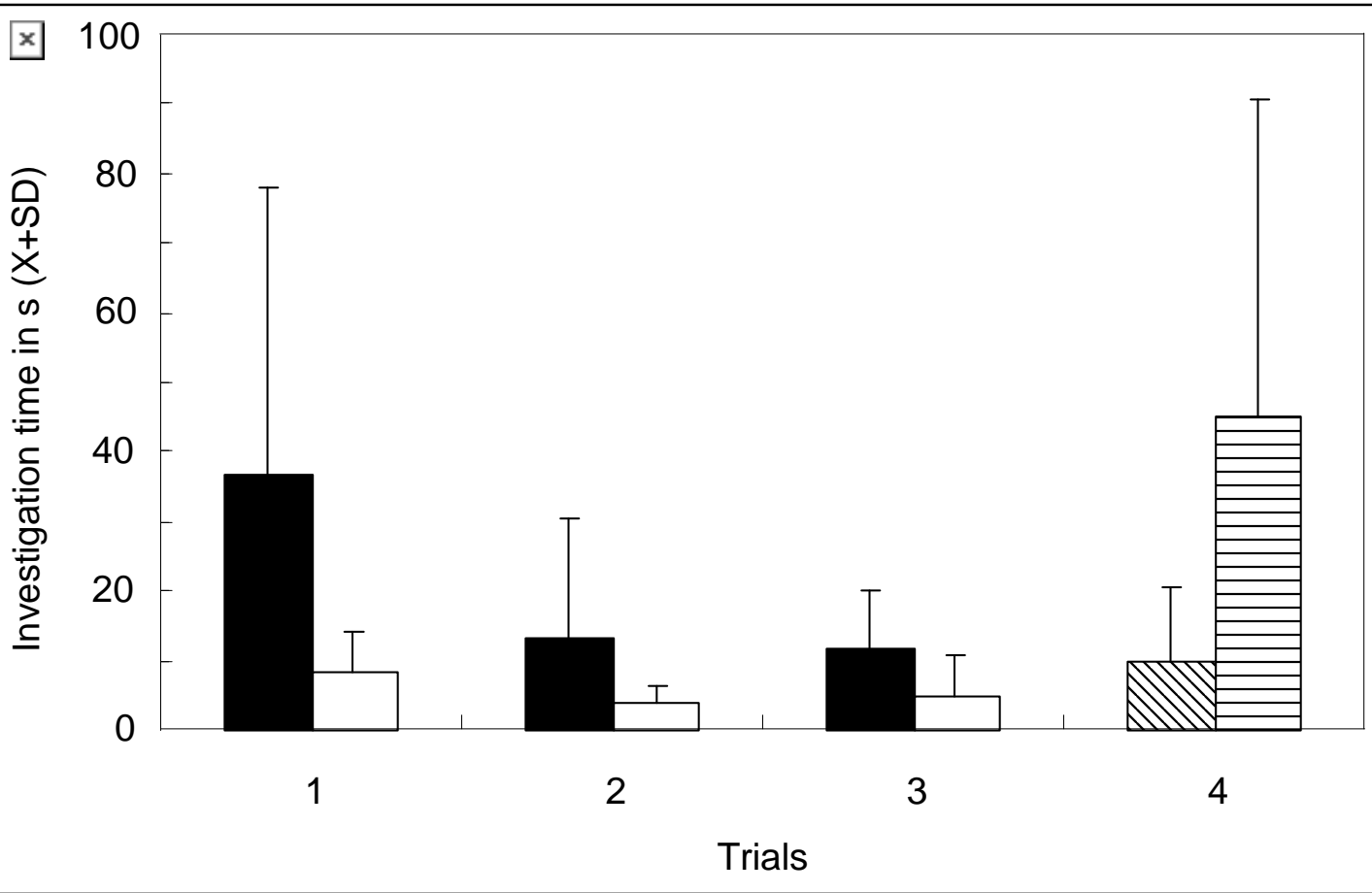

6

7

8

Fig. 3 
1
2
3
4

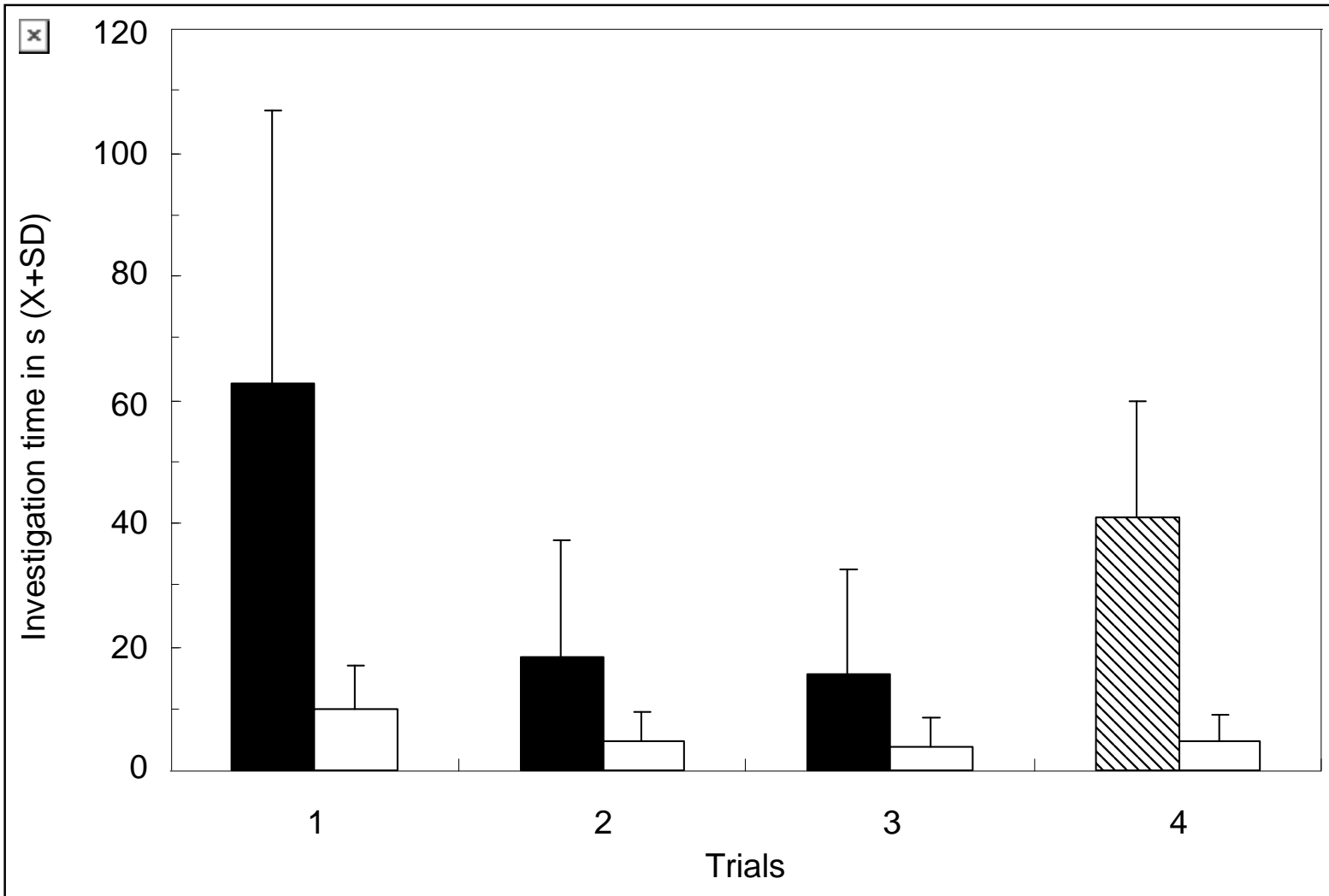

6

7

8

9

10

11

12

13

Fig. 4 
1
2
3
4
5
6

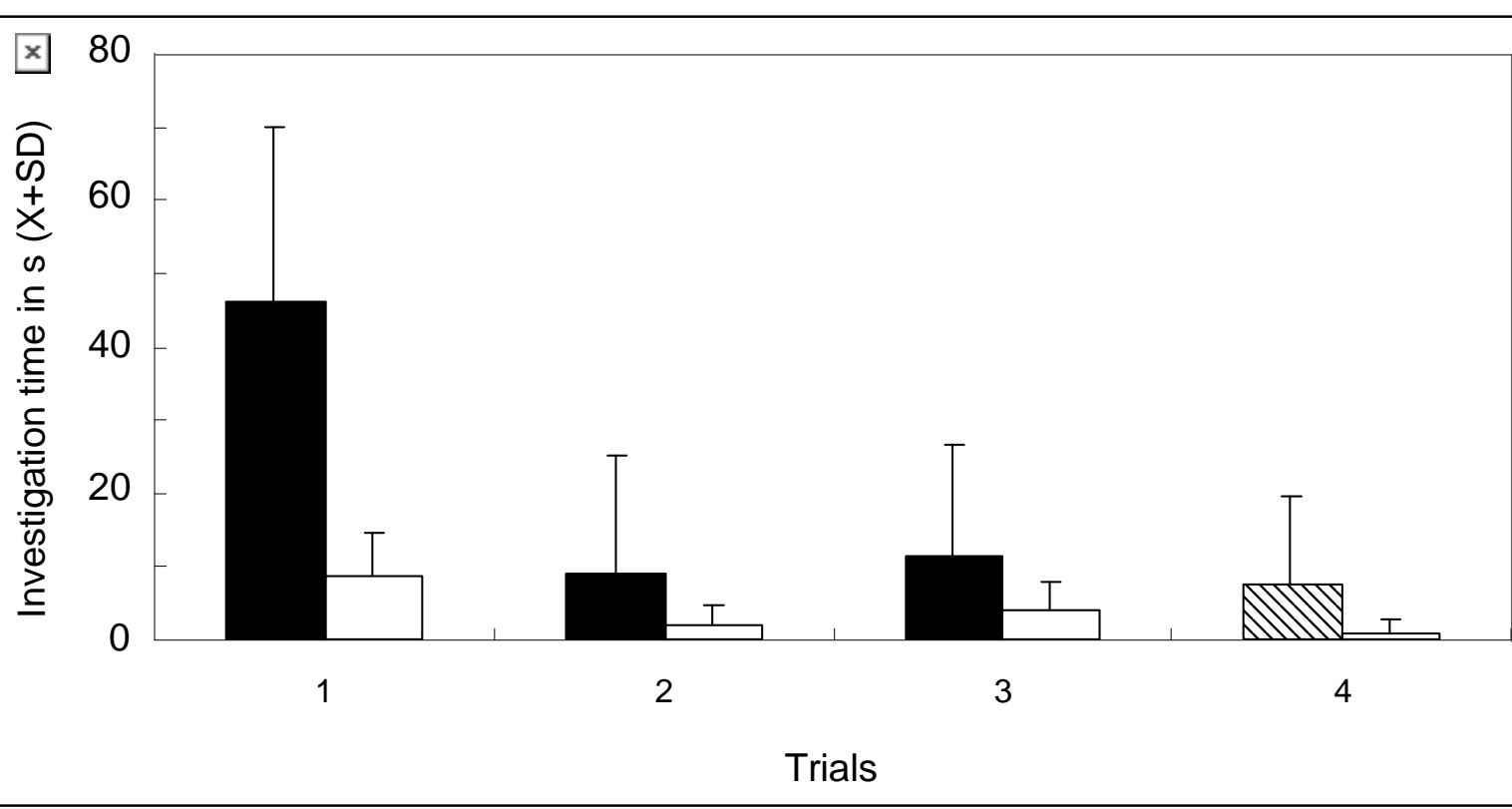

8

9

10

Fig. 5 
1
2
3
4
5

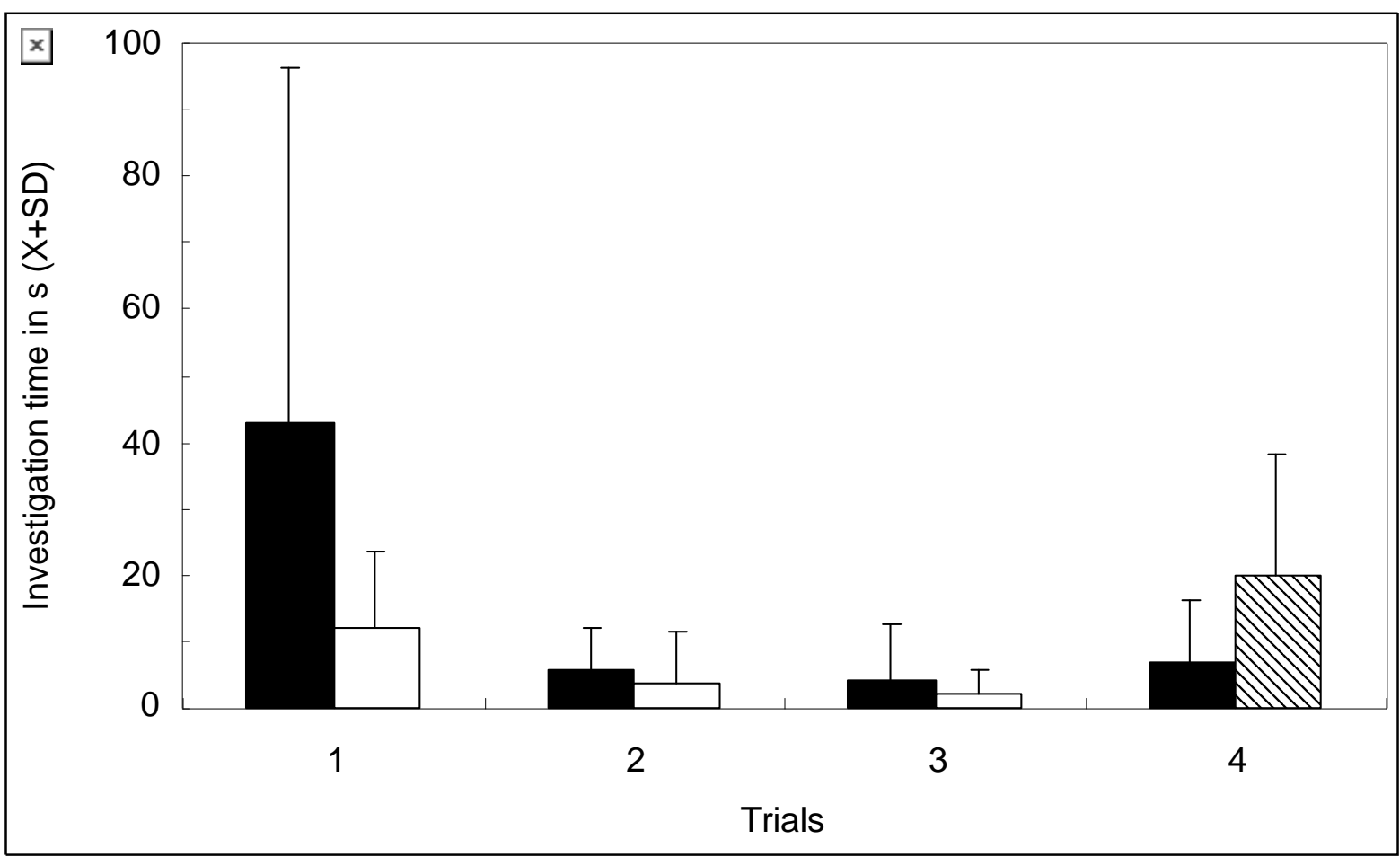

7

8

9

10

11

12

Fig. 6

13 